\title{
القومية ونظـرياتها
}

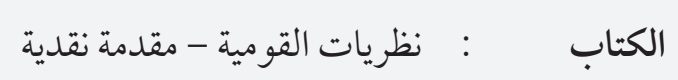$$
\text { الكاتب : أوموت أوزكيريملي }
$$

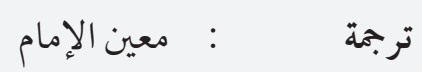

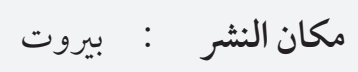

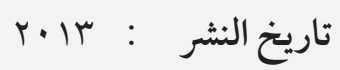$$
\text { الناشر المركز العربي للأبحاث ودر اسة السياسات }
$$$$
\text { عدد الصفحات: ع ع ع }
$$

فضاءات و ميادين بحثية جديدة، واعتناق وجهات نظر إبيستيمولوجية (معرفية) جديدة، واستثمار رؤى علم النفس الاجتماعي والطب النفسي في

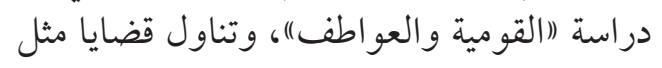
("القومية والإنترنت) و ((الوطنية الغريبة)" ... إلخ.

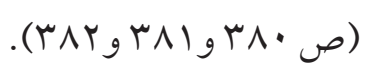

وإذ يحاجج المؤلّف في عدم إمكان تحديد تاريخ

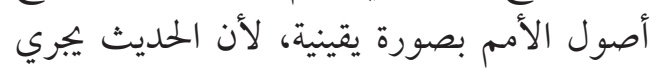

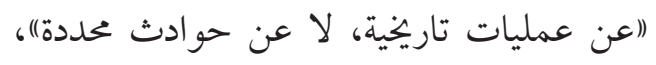
ويدور حول (إشّكالية تحديد الأمة))، فإنه يضع

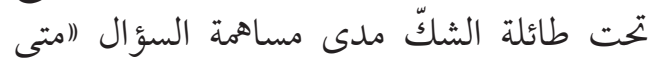
ظهرت الأمة؟)، في فهم القومية، ويقسم النظريات

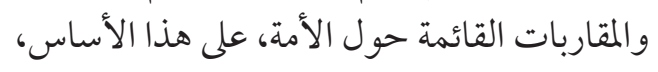

ينهي أوموت أوزكيريملي، بعد نقاش

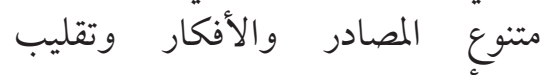
النظريات بشأن القومية، بالسؤال عن الدراسات

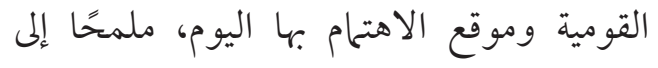

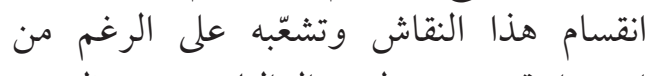
استمرار تمحوره حول سؤال التاريخ: متى ظهرت

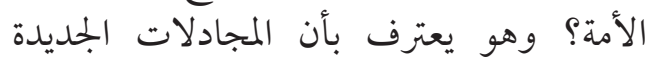

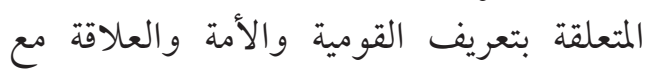

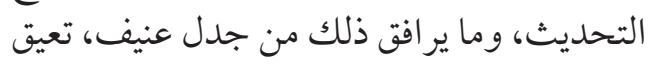

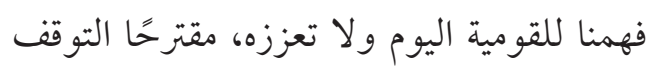

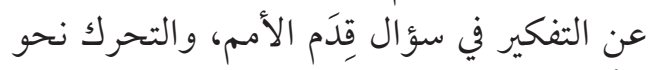

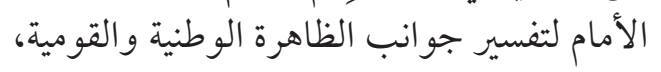

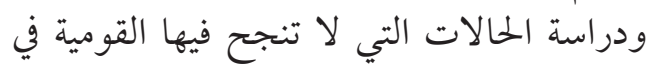
حشد الجماهير، وفتح ججال دراسات القومية أمام 
الأكاديمي، مع انتشار النزاعات الإثنية والقومية

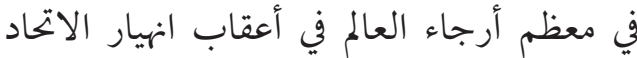

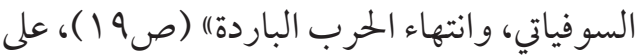

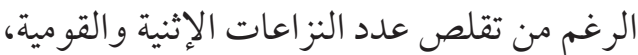

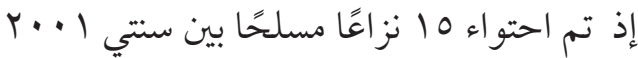

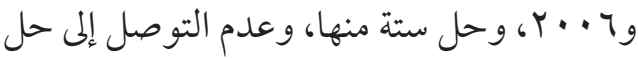

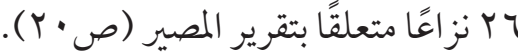
يحاول المؤلف تفسير هذا التباين بين البيانات المتو افرة و المدركات الأكاديمية والشعبية الشائعة،

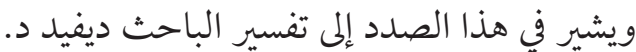

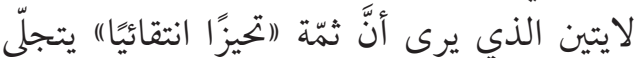

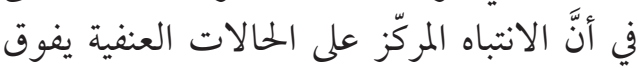

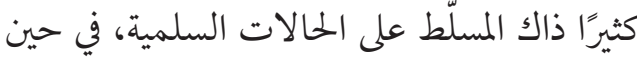

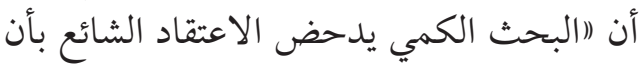

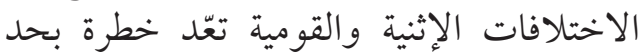

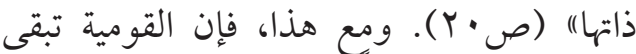

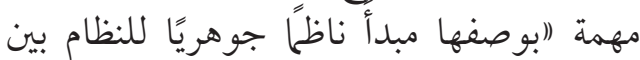
الدول، ومصدرًا نهائيًا للشرعية السياسية، وإطارِارًا

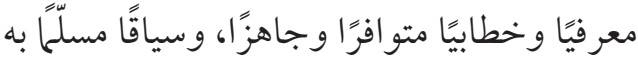

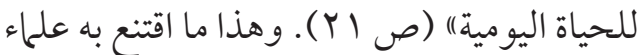

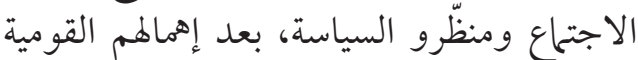

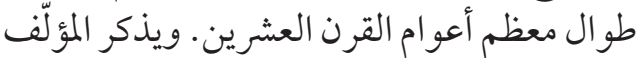
أنه باستثناء الأعمال الريادية لمؤرخين، أمثال

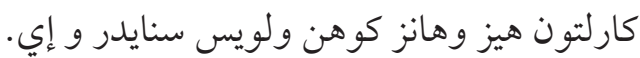

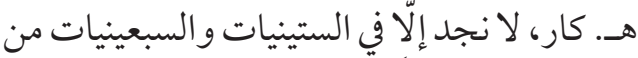

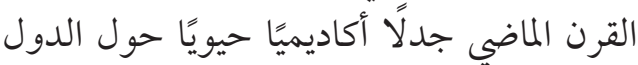
القومية، استحثثه تجربة التحرر من الاستعارئاريا وحفزه ظهور الدول الجديدة في آسيا وأفريقيا. وعدّت أغلبية الدراسات التي دعمت نسخة من الدئ

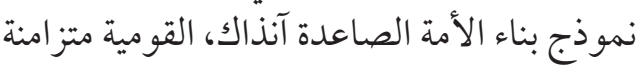
مع عمليات التحديث، ونتيجة أو منتجًا جانبيًا

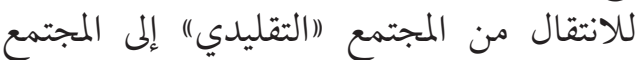
(الحديث)، ثم انتقل الجلدل إلى مستوى جديد كليًا

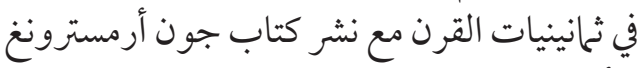

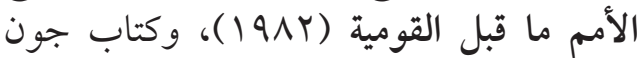

إلى فئات نختلفة تراوح بين أتباع النظريات البدائية

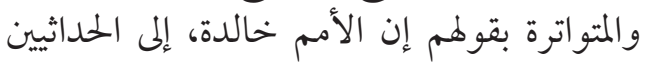

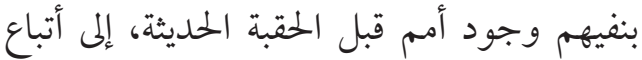

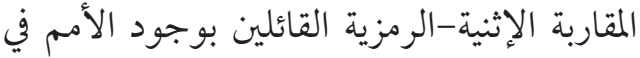

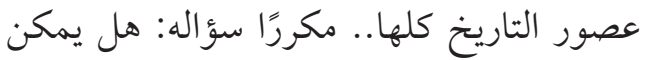
أن توجد نظرية شاملة للقومية؟ ومعتقدًا أن أفضل طريقة لفهم القومية هي المقاربة (البنائية الاجتماعية)

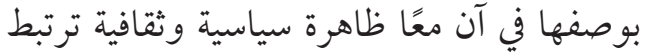

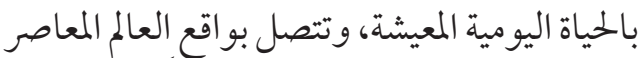

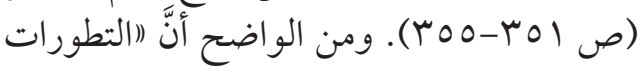

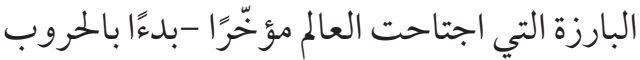

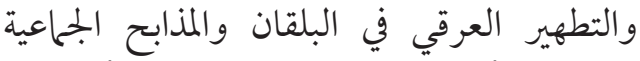
في وسط أفريقيا، مرورًا بالنزاعات الأهلية في الفي الميات

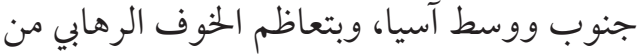

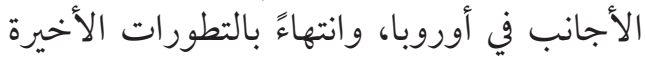

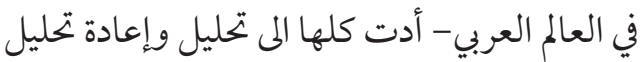

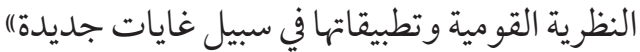

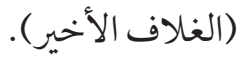

\section{تكاثر الإصدارات}

يعرض أوزكيريملي لأهم المناقشات والمجادلات

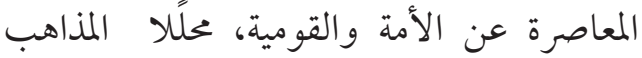
والمقاربات التي طرحها أبرز المنظرين القوميين

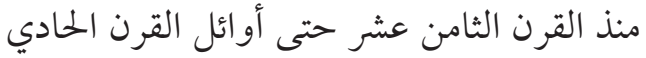

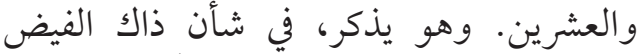

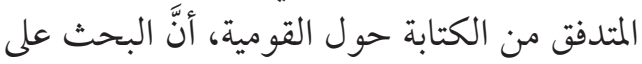
موقع مكتبة أمازون على الشبكة الإلكترونية الئلية

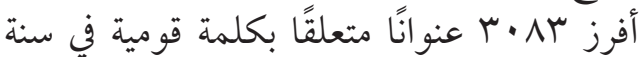

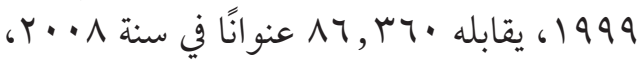

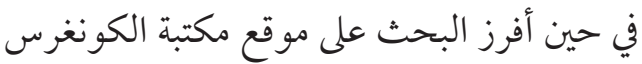

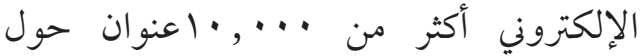

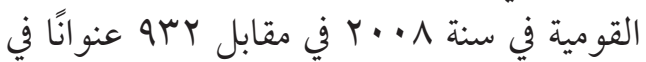
سنة ... (ص) (صوه).

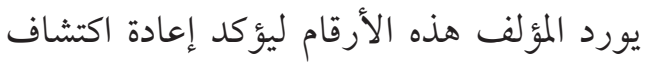

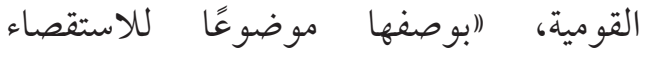


القومية، محددًا أربع مر احل من التفكير في القومية

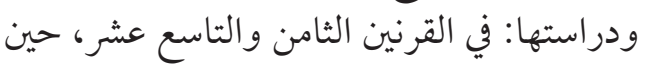

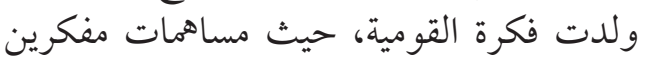

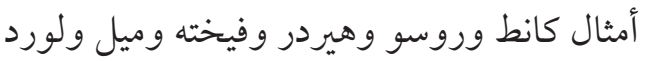

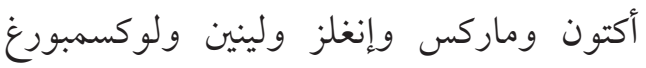
وباور وستالين ومؤرخين مثل دوركهايم وفيبر.

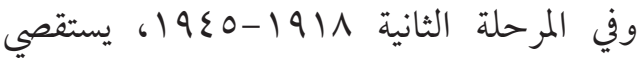
أعحال كارلتون وهيز وكوهن ولويس سنائ المايدر، حين أصبحت القومية مادة استقصاء أكاديمي.

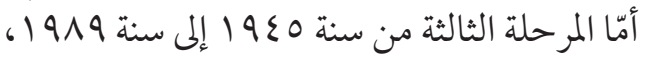
فشهدت مساهمات منظرّي التحديث مثل دانييل ليرنر ودويتش وإيلي خدوري حيث أصبح الجدات الجدل

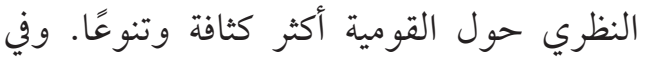

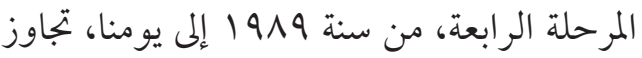
النقاش الجدل الكلاسيكي بشأن القومية.

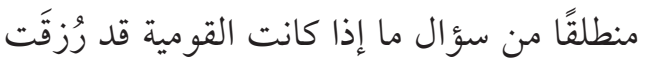

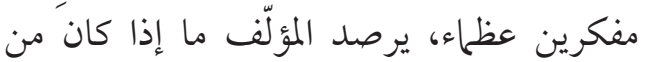

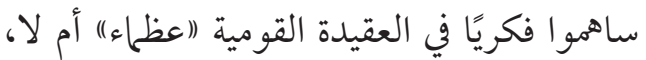

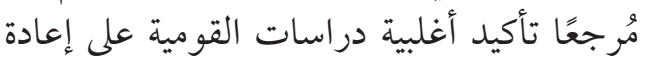

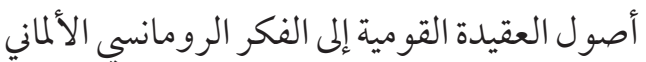

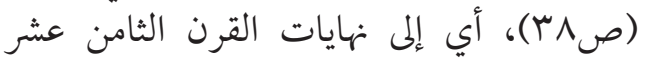

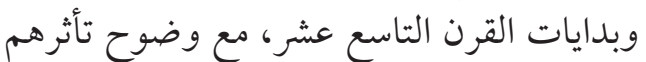

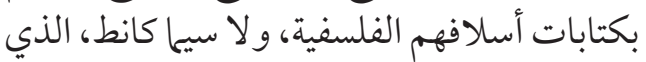

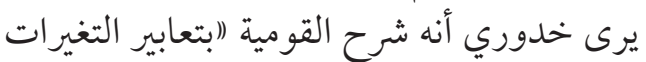

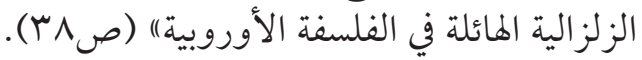

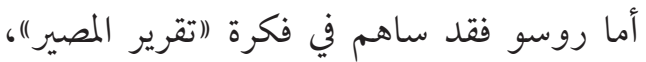

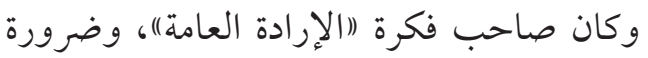

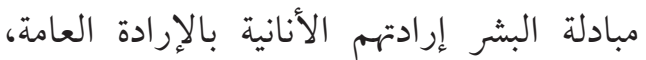

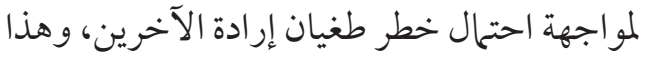

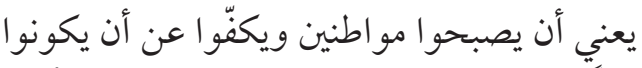

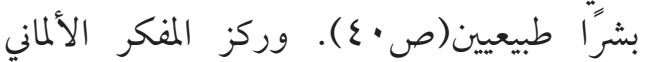
هيردر على (فرادة الثقافات الوطنية) ولغة الآلياء

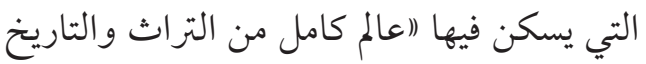
ومبادئ الحياة وقلبها وروحها)، (ص (ع ع) )، متميزًا بذلك عن روسو ومفكري عصر التنوير. ومثله
برويللي القومية والدولة (YA91 ) و وكتاب بندكت

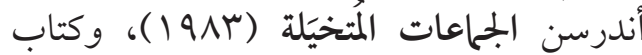

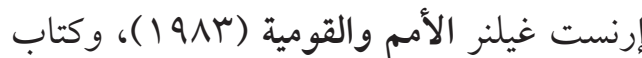
إريك هوبزباوم وتيرنس رينجر اختراع الإن التراث

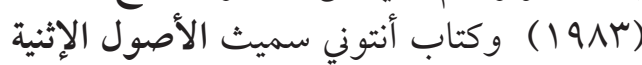

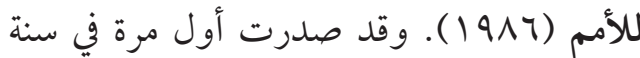
19V 1 أجلة أكاديمية تعنى بالقومية وأدبياتها.

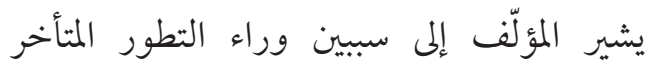
للأدبيات المكتملة عن القومية، أولملما حالة الماتل

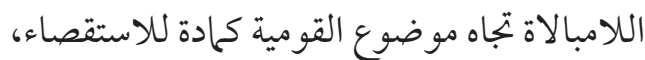
والصرامة العلمية للفروع المعرفية التي علتهّا

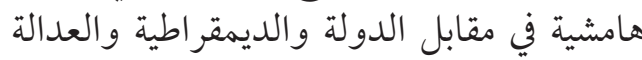

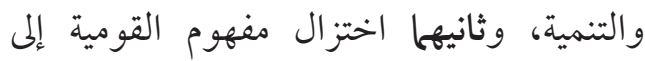
تطرف الحركات الانفصالية والسياسات اليمينية.

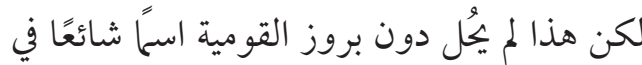

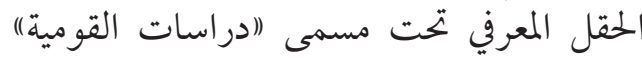

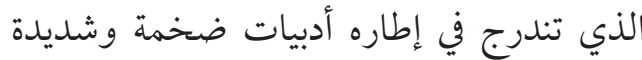

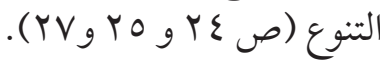

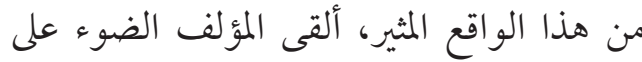

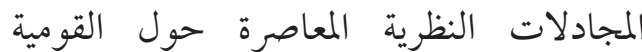

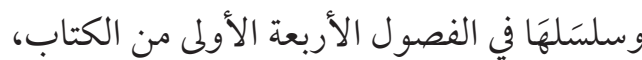

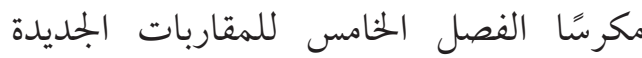

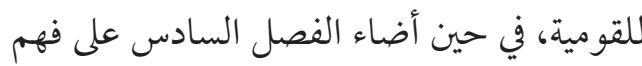

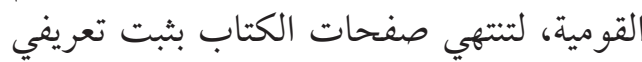

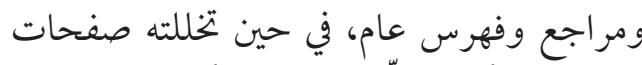

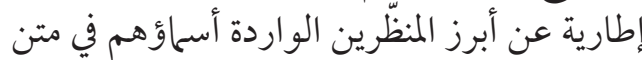

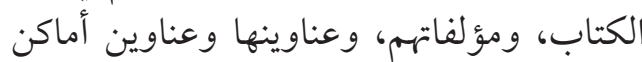

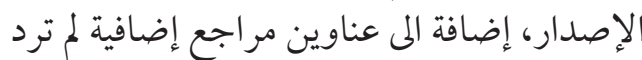
في الكتاب بغية تحقيق المزيد من الفائدة.

\section{مراحل التفكير بالقومية}

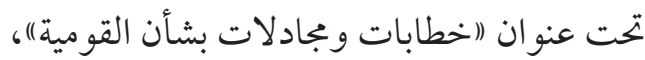

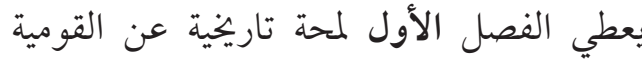

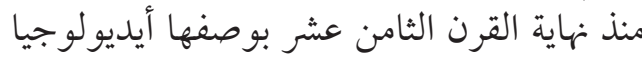
وحركة اجتماعية وسياسية، وعن ارتقاء فكرة الثرنيا 
الصهيونية في صيف 19 19 تحت تأثير كارل بوبر

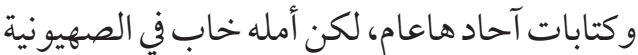

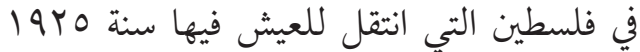
بسبب اندلاع العنف بين اليهودو الفلسطينيين.

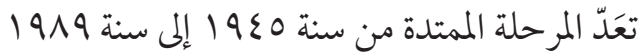
الحقبة الأكثر كثافة وغزارة في الأبحاث المتعلقة

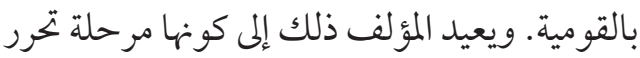

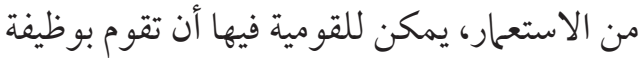

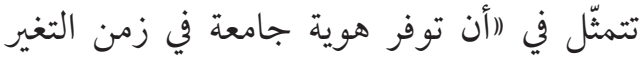

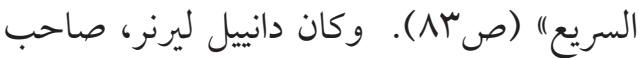
كتاب موت بجتمع تقليدي (1901 ) )، نمو ذججا أصليًا

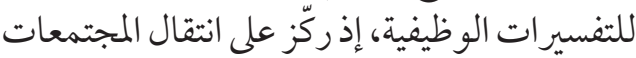
من القيم التقليدية إلى الحداثة عبر مرحلة التيلة انتقال

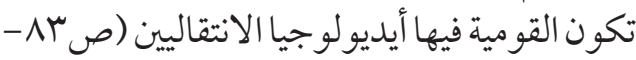

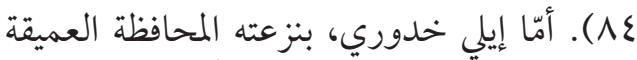

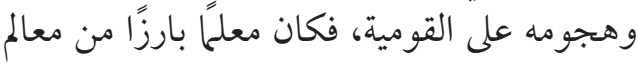

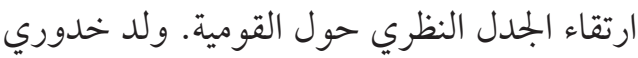

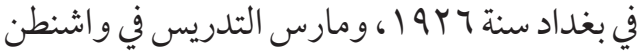
وتوفي فيها، ويُعتبر من أهم المرجعيات العالمية في العيد

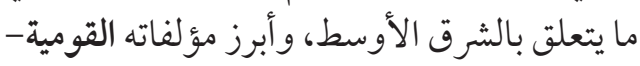
. 197 والقومية في آسياوأفريقيا- • 197.

\section{البدائية}

يتناول الفصل الثاني من الكتاب مفهوم (البدائية)"

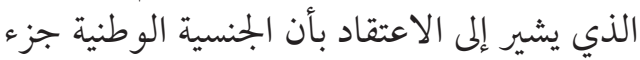

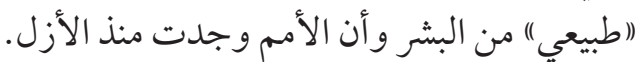

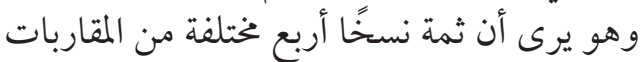

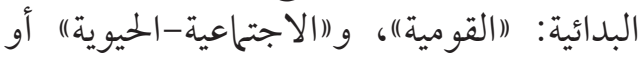

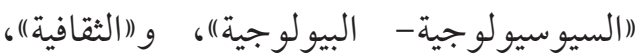

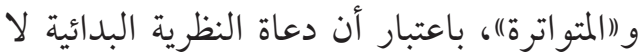

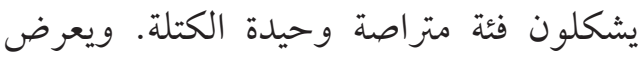

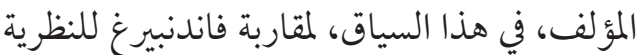

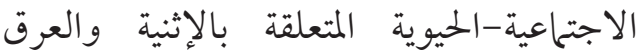

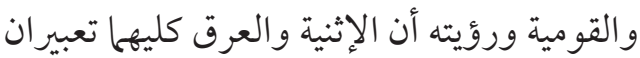

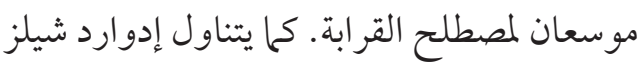

آمن الفيلسوف فيخته بـا(فرادة الأمة الألمانية)

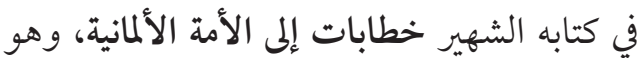

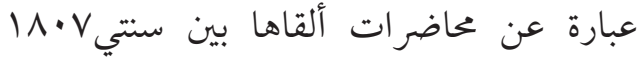

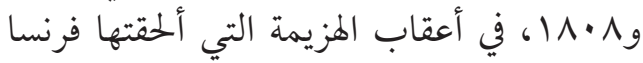

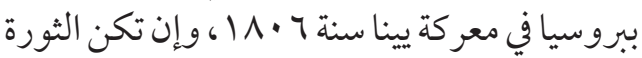
الفرنسية أهم مصدر سياسي لفكرة القومية، نظرًا

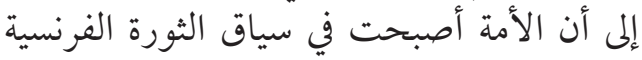

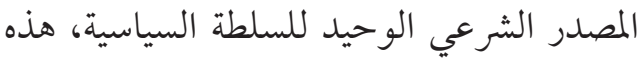

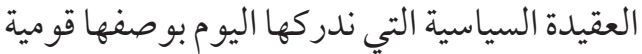
ترسخت في أواخر القرن التاسع عشر (صل عـ ). وثمة جدل كبير حول مساهمة الماركسيين والليبراليين في المسألة القومية، شأنهم شأن المان

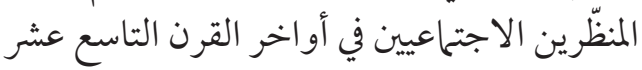
وأوائل القرن العشرين. يميز هانز كوهن، من المر حلة الثانية المشار إليها آنفًا، بين نوعين من القومية بقوله: (اولدت القومية الغربية التوانية

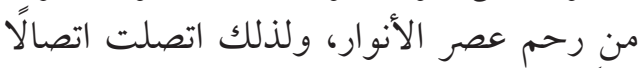

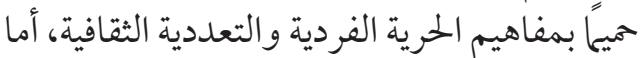

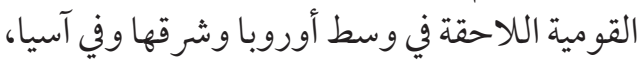

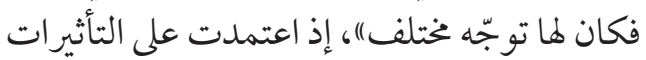

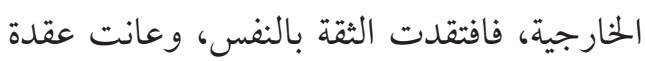

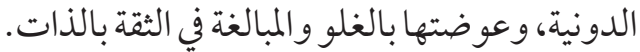

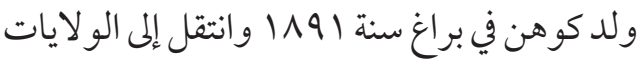

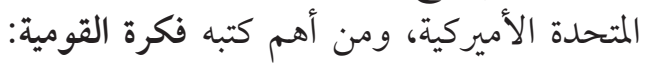

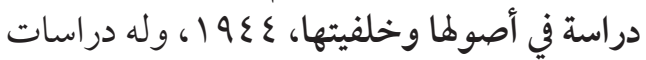
أخرى في هذا المجال. ويذكر المؤلف أن أنمان اهتحام

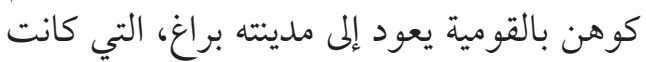

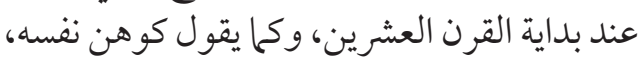

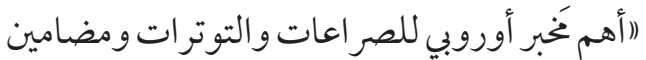

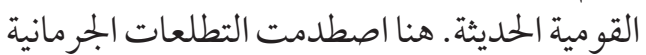

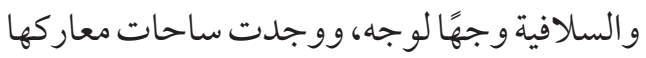

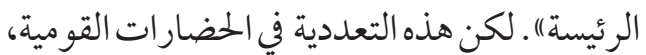

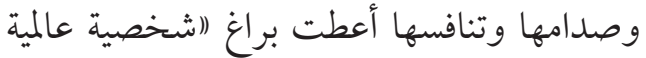

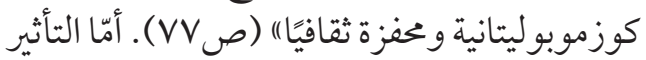
التكويني الآخر في أفكار كوهن، فكان إنيان اعتناقه 
الى رؤية القوميين أن الجنسية الوطنية سمة متأصلة

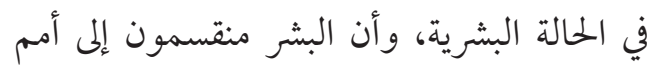

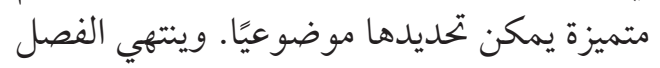
بتسليطه الضوء على النظرية البدائية اليوم، لنسمع ويتهي الفهل

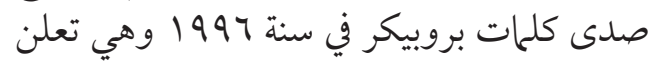

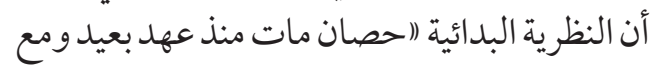
ذلك يو اصل كتّاب الإثنية و القومية حثه بالسياطان)،

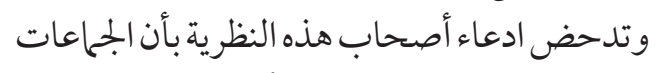

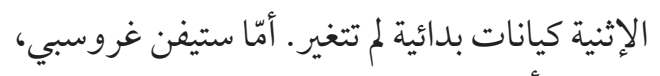

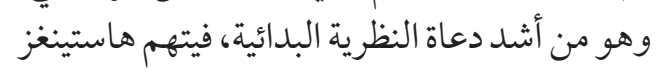

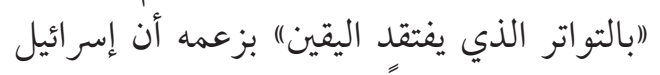

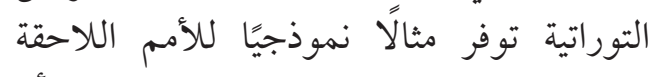

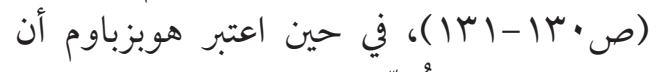

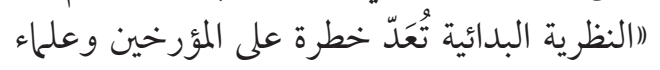

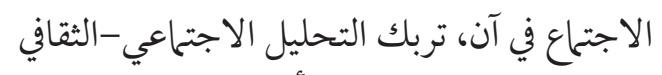

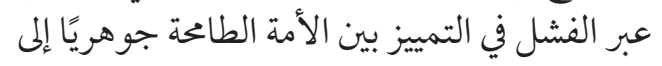

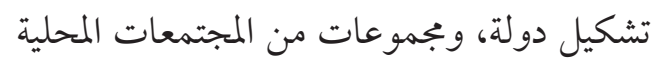

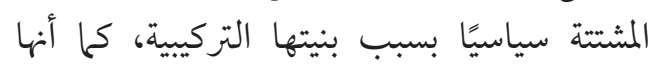

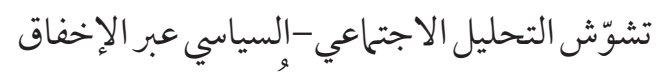

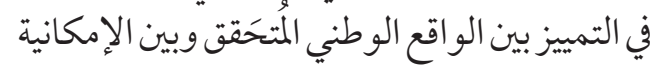

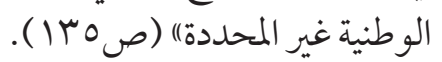

\section{الحداتٔة}

يتضَاد الحداثيون في نظرتهم إلى موقع القومية

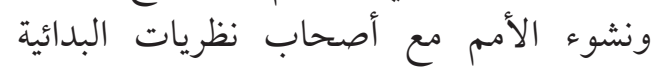

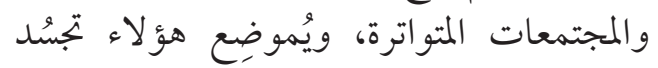

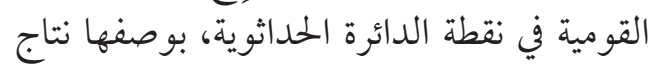

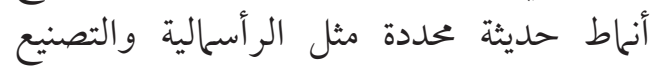

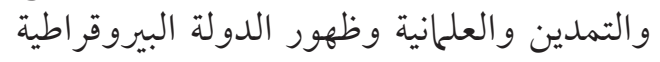

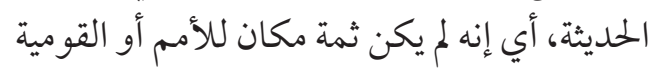

$$
\text { في الحقبة ما قبل الحديثة. }
$$

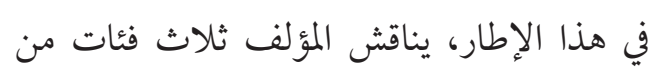

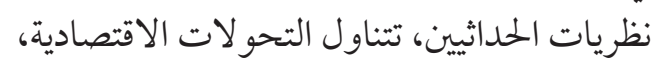

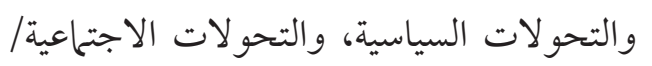

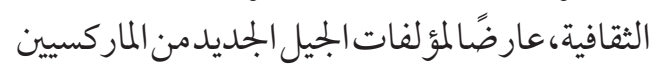

وكليفورد غيرتز ومقاربتها الثقافوية، وأفكارهما

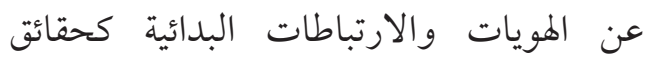
مقبولة وبديهية وأصيلة وسابقة على التجارب الابت كابت

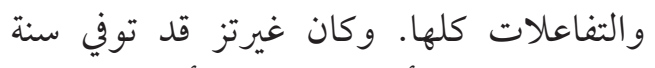

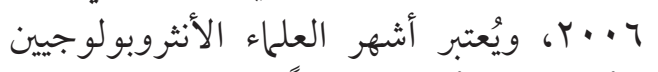

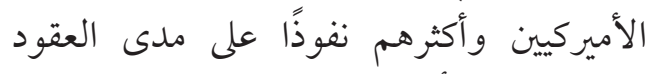

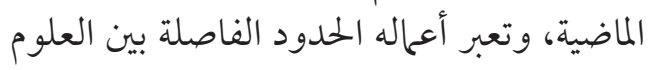

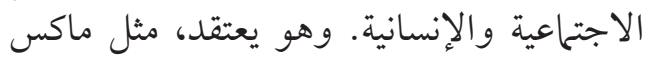

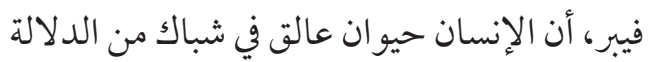
نسجها بنفسه، والثقافة في رأيه هي هذه الإنسان الشّبّاك،

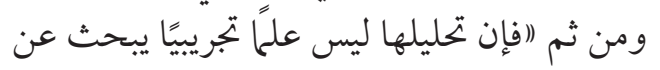

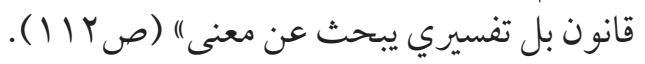

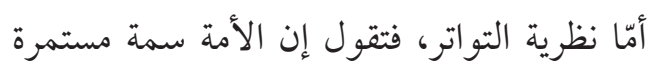
وجوهرية للحياة البشرية على مدى التاريخ المدوّن.

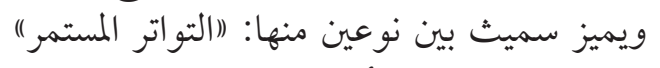

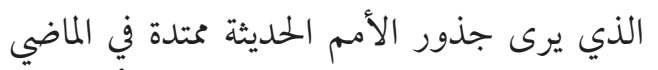

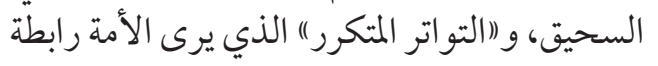

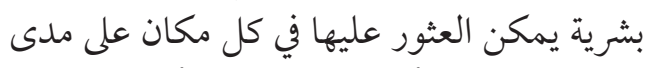

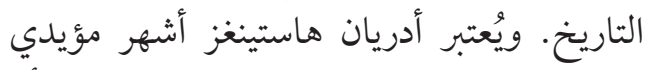

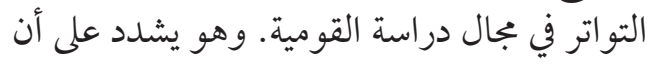

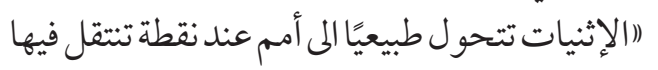

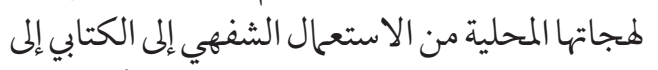

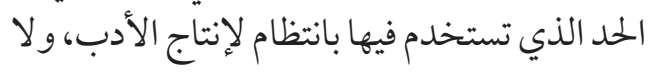

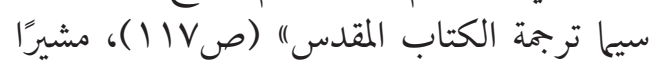

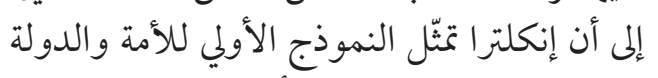

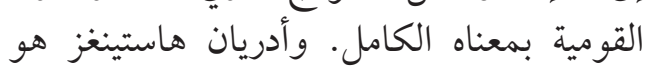

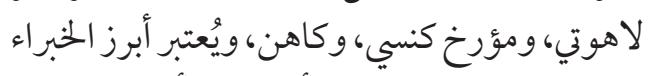

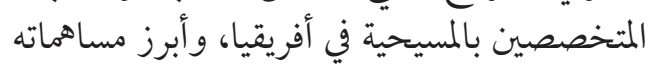

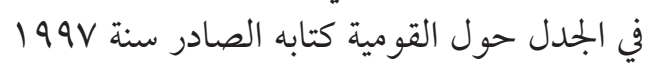
بعنو ان بناء الأمة، ويتضمن سلسلة محاضراته في في العابه جامعة كوين في بلفاست. لم يغفل المؤلف التّهُم الموجَّهة إلى المقاربات البدائية،

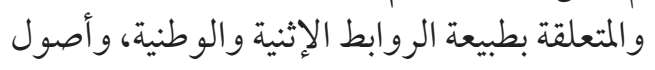

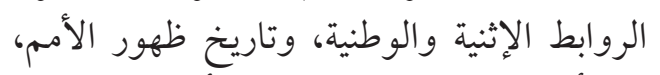
ومسألة العاطفة والشعور، من دون أن يغفل الإشارة 


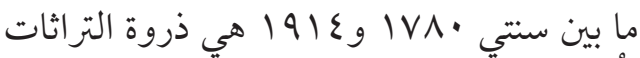

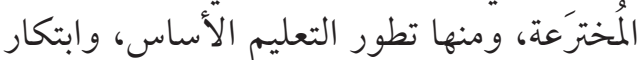

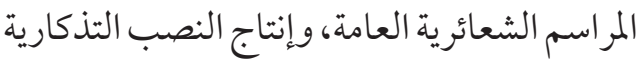

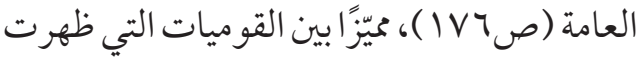
في أواخر القرن العشرين، و الم تعد مسارًا رئيسًا

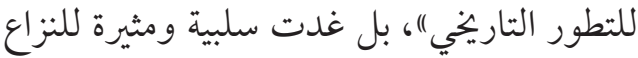

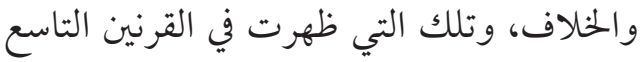

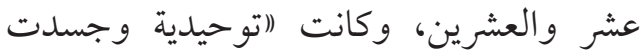

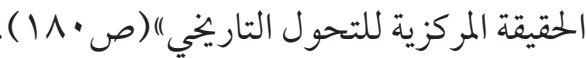
وفي باب التحولات الاجتماعية-الثقافية، ناقش إنش

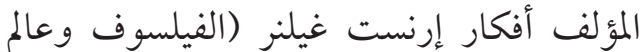

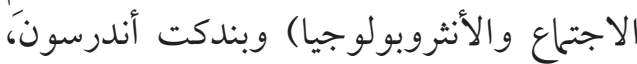

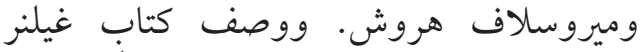
الفكر والتغيير( (97 197) بأنه الأكثر نفوذًا وتأثيرًا

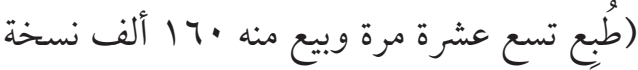

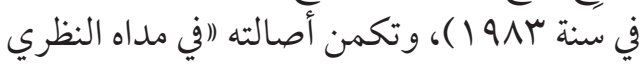

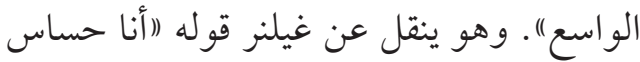
في العمق لسحر القومية الطاغي، وأستطيع أن فئن

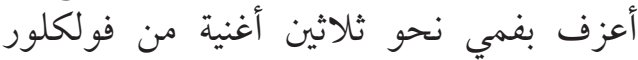

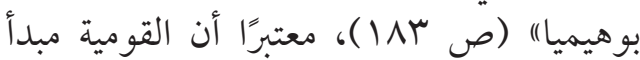

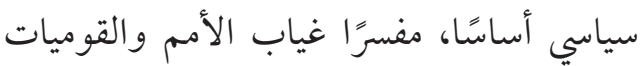

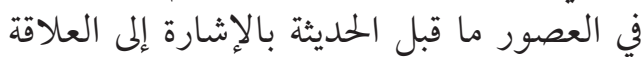

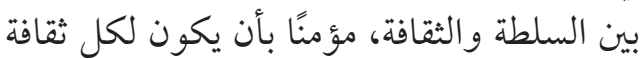

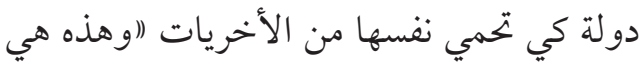

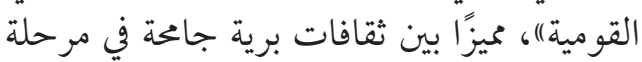

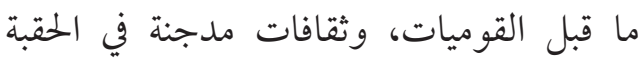

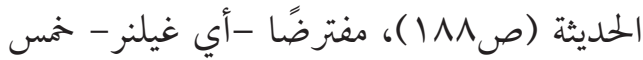

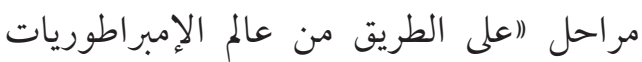
غير الإثنية والوحدات المصغرة إلى عالم الدون الدول

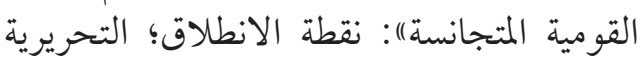

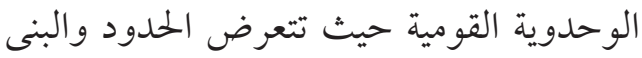

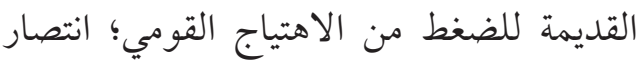

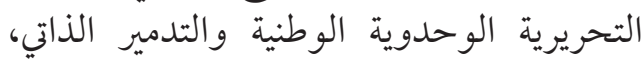

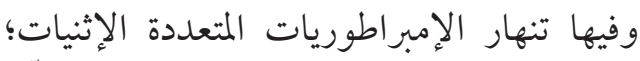
و (الليل والضباب)، وهو تعبير نازي وفيها تعلّق
وإعطائهم ثقاً أكبر لدور الثقافة والأيديولوجيا

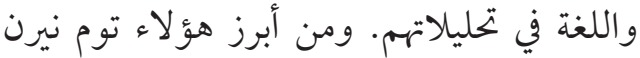

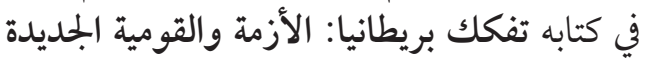

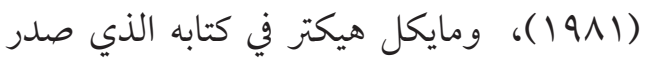

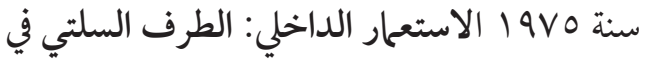

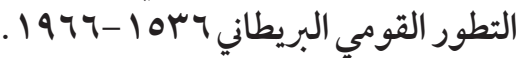
يرى نيرن أن القوميات تحتوي على بذور التقدم التيط

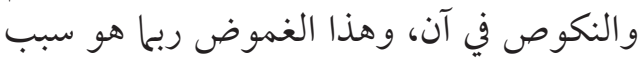

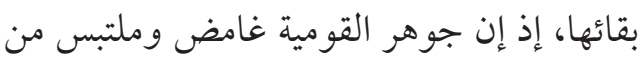
الناحيتين السياسية والأخلاقية، لكنه يضيف إنهائ

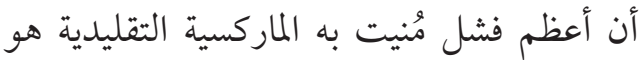

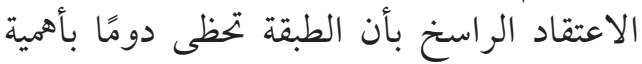

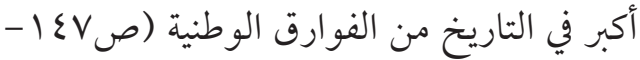

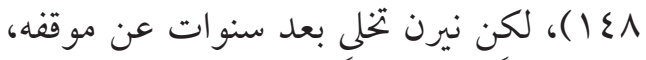

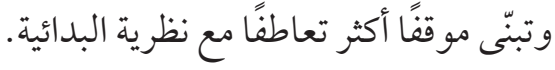
وفي باب التحولات السياسية لتفسير القومية،

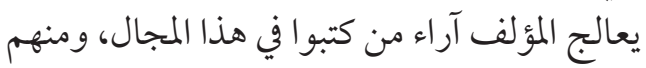

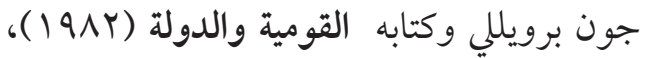

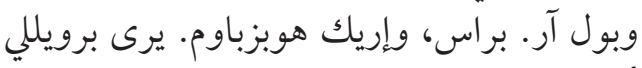

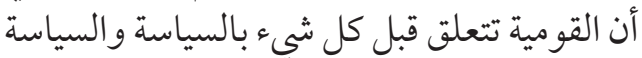

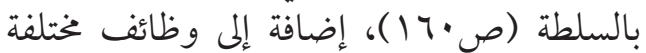

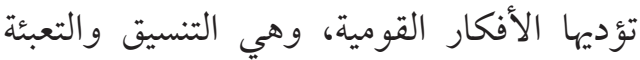

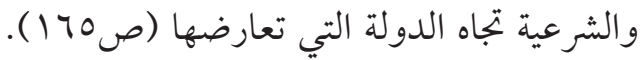

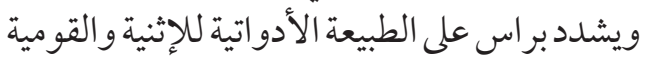

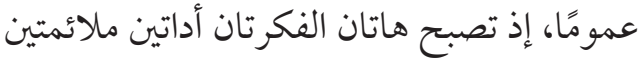

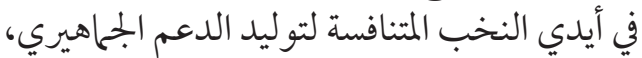

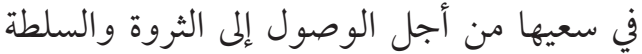

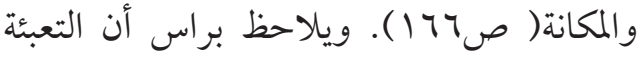

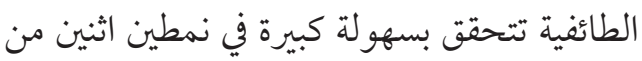

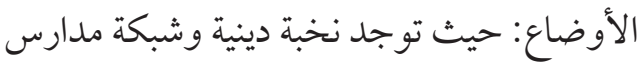
دينية، وحين تعترف سلطات الدولة باللغة المحلية

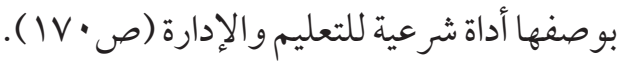

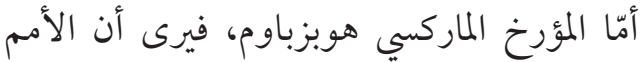

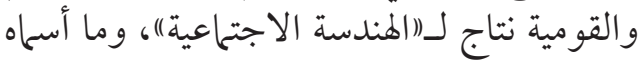

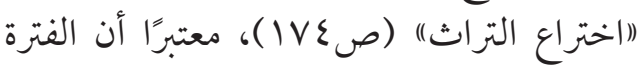




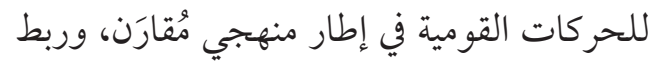

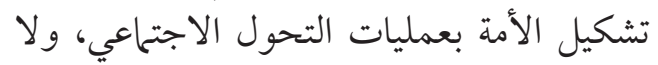

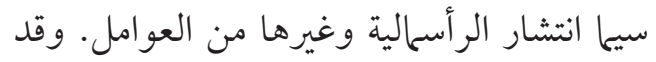
عرف قارئ الإنكليزية كتابات هروش عبر الترالية كتابات

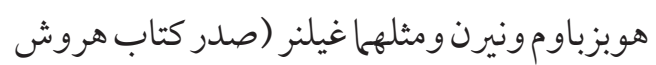
الشروط الاجتحاعية للانبعاث القومي في أوروبانيا

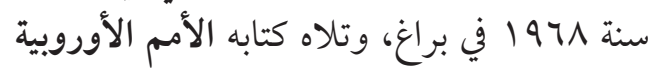

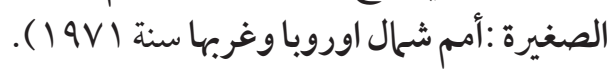

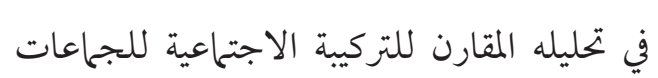

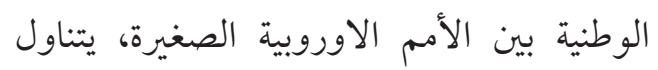

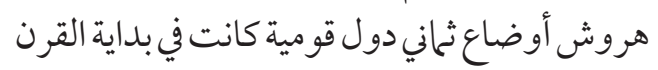
التاسع عشر في أوروبا، بلغاتها الأدبية المتطورة،

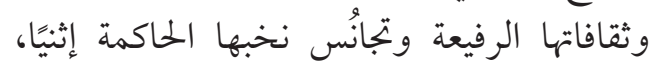
هذه الدول هي إنكلترا وفرنسا وإسبانيا والسويد

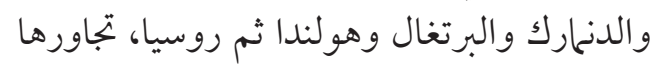
أهتان بازغتان هما ألمانيا وإيطاليا المتطور روتان ثقافيكًا

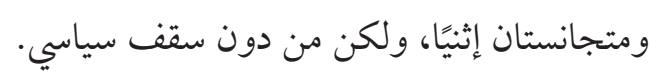
وكان هناك في الوقت ذاته أكثر من ثلاثين (اجماعة إثنية غير مهيمنة) يلفت هروش الانتباه إنى إلى ارتباطها

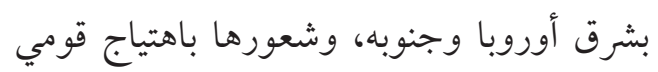

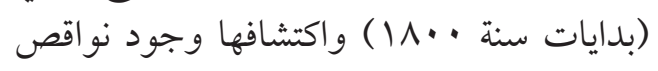

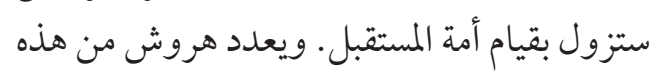

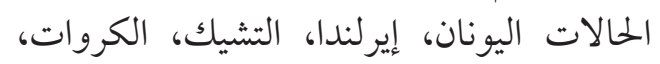

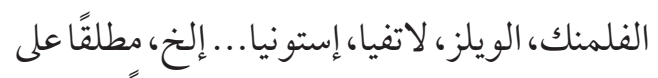

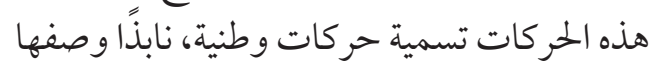
بالقو مية، فالقومية ليست سوى شكل من الأشية لأشكال

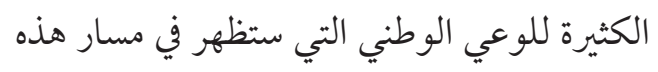

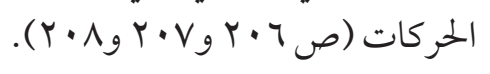

يفرد المؤلف صفحات لنقد الحداثيين على يد

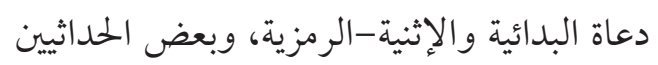

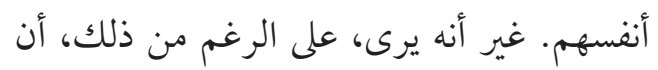

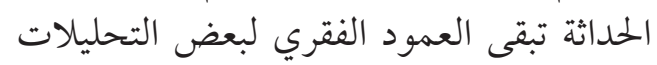
البالغة التأثير والنفوذ في ما يتعلّق بالقومية.
المعايير الأخلاقية، ويطبق مبدأ القومية الذي

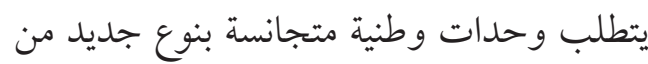

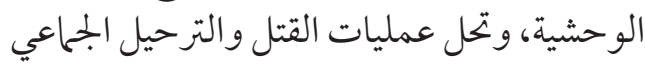

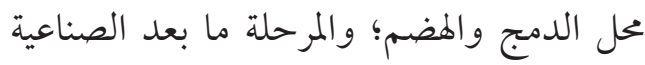

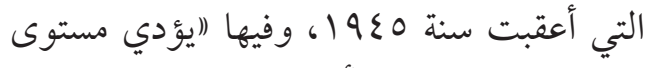

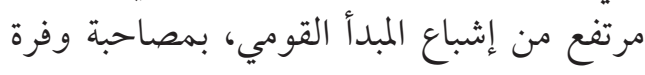

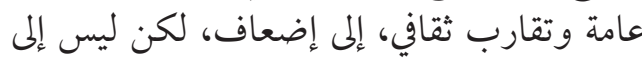
اختفاء، خبث القومية) (ص • (19 - 19 19).

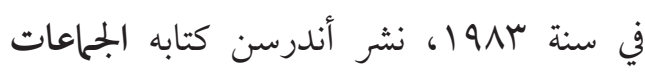

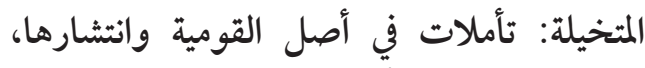
وصف فيها الأمم بأنها (اجماعات متخيلة)، مؤكدًا أن (القومية ظهرت قرب نهائ نهاية القرن الثامن عشر

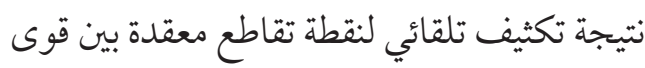

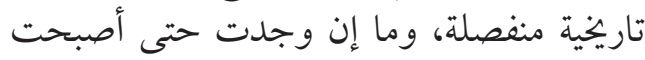

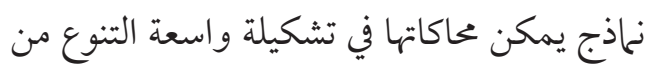
البيئات الاجتماعية بواسطة تشكيلة واسعة من فئن الأيديولوجيات ذات الصلة) (ص ع 9 (1)، معرّفًا

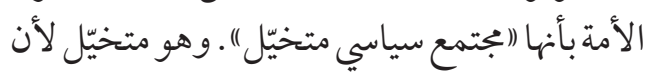

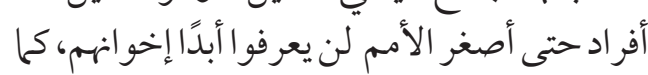

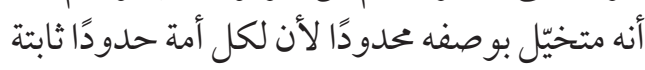
ومعينة تقع خلفها أمم أخرى (ص ع 19 1) ).

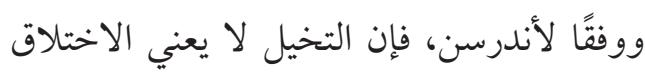

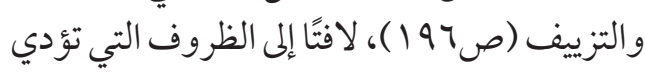

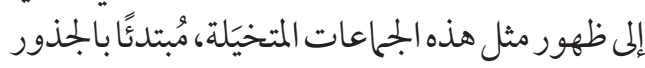

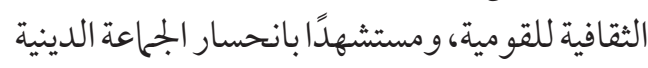
والممالك الوراثية في أورويا وما وفرته من حيّة حيّز

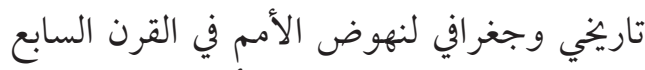

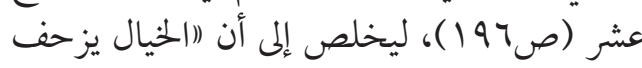

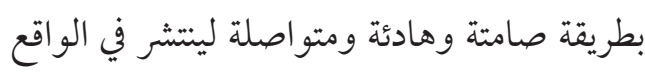

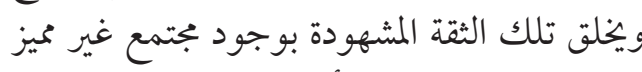

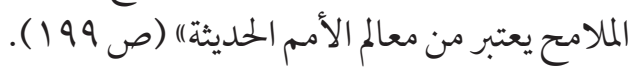

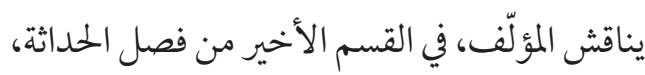

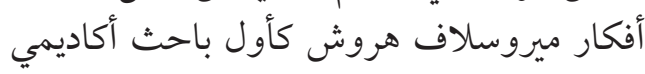
عمل على التحليل الاجتماعي-التاريخي الكمي مئوني آنادي 


\section{الإثنية - الرمزية}

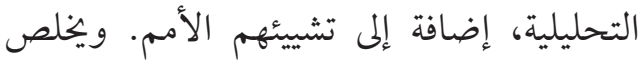

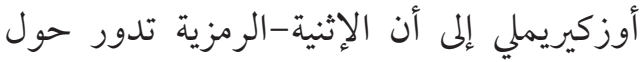

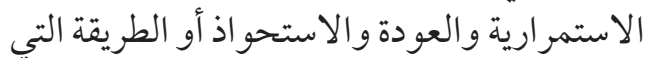

يقيد بها الماضي الحاضر (إسرائيل نموذجَا).

\section{مقاربات جديدة}

يسند المؤلف قوله بمر حلة جديدة من مر احل الجدل النظري حول القومية إلى ما شهلدته نهاية ثمانينيات

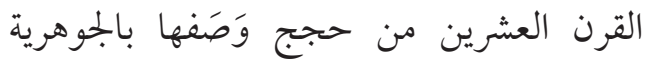

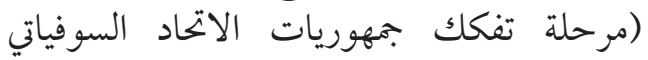
والدول المجاورة)، ودفق الدراسات النقدية تجاه

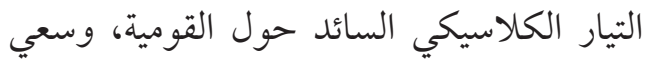

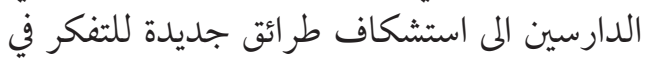
الظاهرة الوطنية. وهو يلاحظ تأثر المقاربات الجلديدة الماتيدة

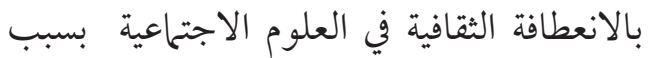

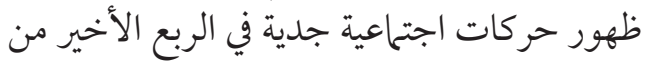

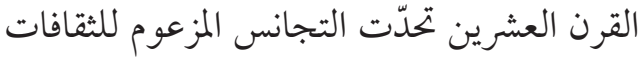

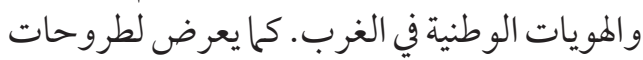

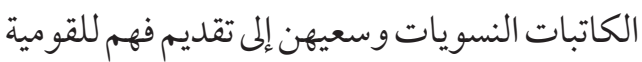

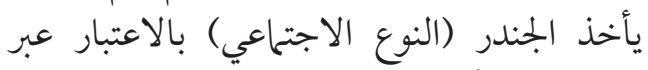

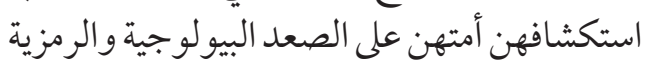

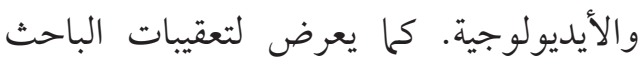

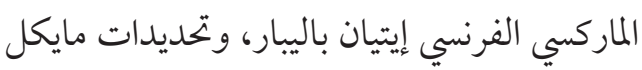

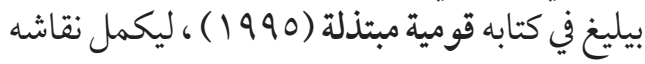

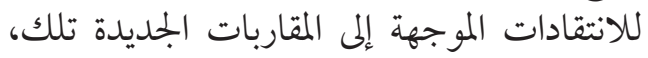

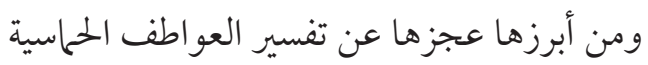

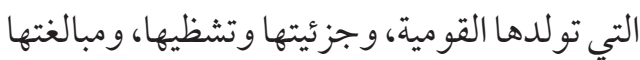

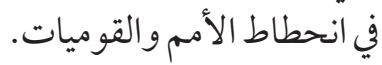

يؤكد المؤلف، في نهاية الكتاب الذي لم يأت قط إلى الى

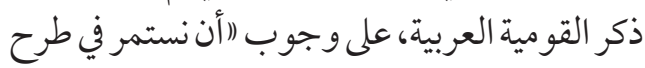
الأسئلة، والتنقيب في عمق منطق القومية، والارتكاز

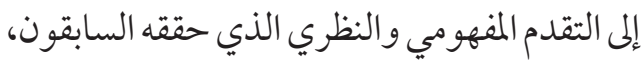

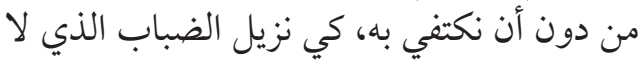

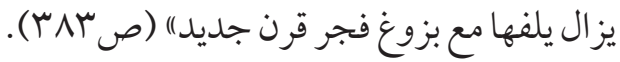

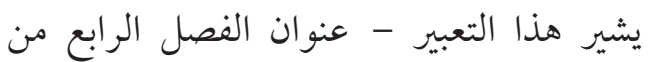
الكتاب - إلى (مقاربة تشدد على دور الأساطير

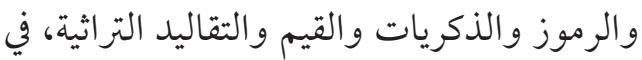

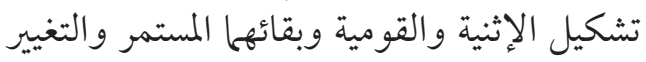

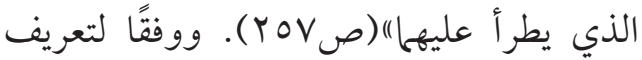
أبرز مناصري هذه النظرية، أنتوني سميث، فإِ إنان هذه المقاربة تشدد على الحاجة إلى إجراء إنطاء تحليل

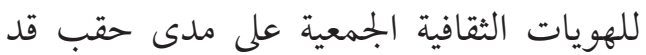

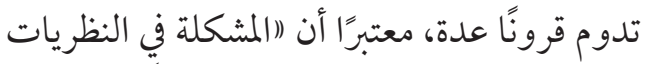

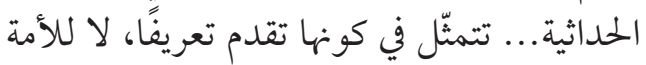

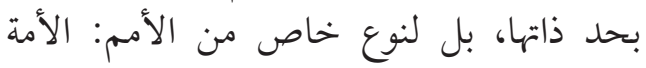

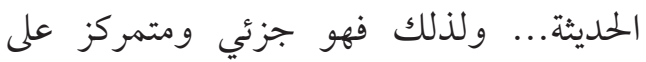

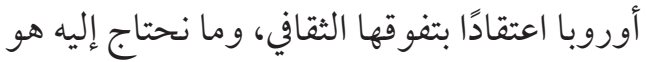

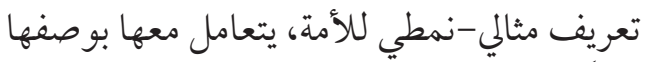

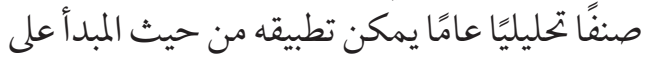

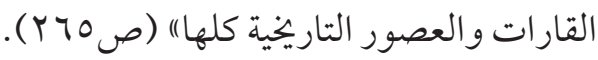

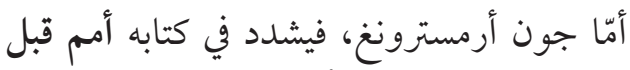

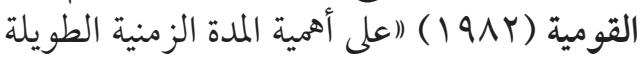

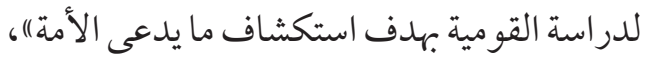

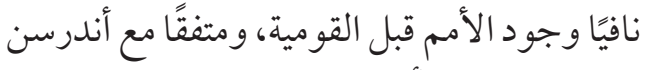

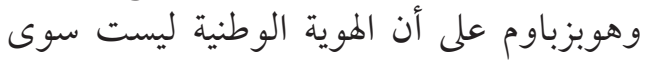

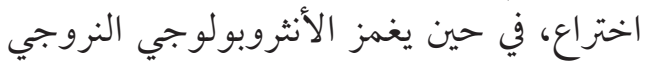

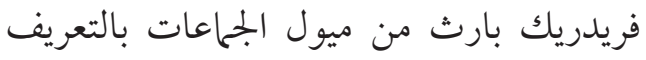

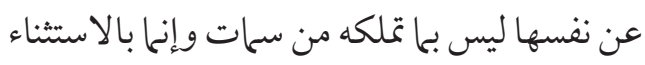

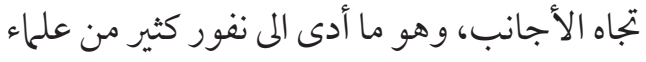

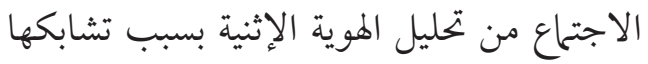

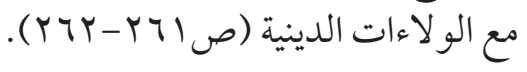

تعرضت النظرية الإثنية-الرمزية لانتقادات شتى، مورك،

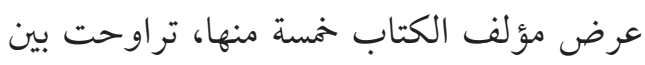

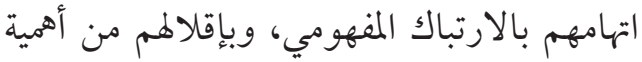
الفوارق بين الأمم الحديثة والمجتمعات الماتِ الإثنية

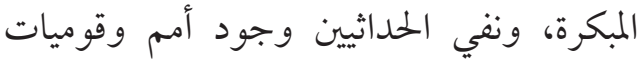
في الحقب ما قبل الحديثة، وافتقار التحليلات المات وتئات 